DOI: https://doi.org/10.24127/ajpm.v10i2.3438

\title{
PENGEMBANGAN MODUL GEOMETRI ANALITIK BIDANG DAN RUANG MATERI KONIKOIDA BERDASARKAN TEORI VAN HIELE
}

\author{
Sulhijrah Mustabil $^{*}$, Nursalam ${ }^{2}$, A. Sriyanti ${ }^{3}$, Suharti $^{4}$, Fitriani Nur ${ }^{5}$ \\ $1^{*}, 2,3,4,5$ Pendidikan Matematika, UIN Alauddin Makassar, Gowa, Indonesia \\ *Kampus 2 Jl. H. M. Yasin Limpo, No.36, Samata 92113, Gowa, Indonesia \\ E-mail: $\quad$ mustabilsulhijrah@gmail.com ${ }^{1 *}$ \\ nursalam_ftk@uin-alauddin.ac.id ${ }^{2)}$ \\ a.sriyanti@uin-alauddin.ac.id $^{3)}$ \\ suharti.harti@uin-alauddin.ac.id ${ }^{4)}$ \\ fitriani.nur@uin-alauddin.ac.id ${ }^{5)}$
}

Received 30 December 2020; Received in revised form 12 June 2021; Accepted 06 July 2021

\begin{abstract}
Abstrak
Penelitian ini merupakan penelitian pengembangan dengan maksud mengembangkan modul geometri analitik bidang dan ruang materi konikoida berdasarkan Teori Van Hiele yang valid, praktis, dan efektif. Penelitian ini menggunakan model pengembangan Plomp yang terdiri atas empat fase, yaitu: fase investigasi awal, fase desain, fase realisasi, dan fase tes, evaluasi, dan revisi. Instrumen yang digunakan adalah lembar validasi, lembar observasi keterlaksanaan pembelajaran, angket respon mahasiswa, angket respon dosen, lembar observasi aktivitas mahasiswa, lembar observasi kemampuan dosen mengelola pembelajaran, dan tes pemahaman konsep. Hasil penelitian menunjukkan modul yang dihasilkan valid, praktis dan efektif, dengan rata-rata kevalidan untuk bahan ajar dan semua instrumen penelitian adalah 4,5. Praktis, dengan rata-rata lembar observasi keterlaksanaan pembelajaran 1,56, rata-rata persentase angket respon mahasiswa 82,68 dengan kategori positif dan rata-rata persentase angket respon dosen adalah 86,94. Efektif, rata-rata persentase aktivitas mahasiswa adalah 80,125, rata-rata persentase kemampuan dosen mengelola pembelajaran adalah 4,00, dan persentase ketuntasan belajar mahasiswa adalah $75 \%$.
\end{abstract}

Kata kunci: Konikoida; modul; pengembangan; teori Van Hiele.

\begin{abstract}
This research form development that refers to development geometrical module analytics field and matter conicoid materials based on Van Hiele Theories which is valid, practical and effective. This research used development of Plomp models that consists of four phases : Investigation phase, design phase, realization phase, and test phase, evaluation and revision. Instrument that used are paper of validation, paper of observation characteristic of learning, questionnaire response of students, questionnaire response of lecture, observation papers activity of students, observation papers the ability of lecture to manage the subject and comprehension test of the concept, result of research show module that valid. Practically and effective. Dengan rata-rata the validation to substance of teaching and all the instrument of research is 4,5 practically. With range observation of papers the characteristic of learning 1,56, range of questionnaire presentation of students response 82,68 for the positive of category and range questionnaire presentation of lecture response is 86,94. Effective, range presentation activity of students is 80,125 , range the ability the presentation of lecture to manage the subject is 4,00, and completeness presentation student learning is $75 \%$.
\end{abstract}

Keywords: Conicoid; development; module; Van Hiele theory.

This is an open access article under the Creative Commons Attribution 4.0 International License 
DOI: https://doi.org/10.24127/ajpm.v10i2.3438

\section{PENDAHULUAN}

Salah satu materi dalam matematika yang harus dipelajari oleh peserta didik adalah geometri. Terdapat banyak manfaat yang diperoleh dengan mempelajari dan mengaplikasikan geometri (Machromah, 2018). Meskipun demikian, geometri masih menjadi suatu poin penting yang dianggap sukar oleh peserta didik (Yudianto, 2017).

Wawancara yang dilakukan kepada salah satu dosen yang membawakan mata kuliah geomentri (geometri analitik bidang serta ruang) menyatakan bahwa para mahasiswa menghadapi kesulitan dalam memahami konsep-konsep dalam materi analitik ruang. Penyebabnya adalah mahasiswa tidak mampu mengidentifikasi bentukbentuk permukaan dari jenis-jenis konikoida. Penyebab lainnya adalah mahasiswa kesulitan dalam mengenal dan memahami jenis-jenis konikoida serta sifat-sifatnya. Selain itu, wawancara yang dilakukan kepada dua orang mahasiswa angkatan 2017 dari jurusan pendidikan matematika di luar perkuliahan, dan wawancara tersebut menunjukkan kurangnya pemahaman konsep para mahasiswa karena sumber belajarnya dalam mata kuliah ini (geometri analitik bidang dan ruang). Dari wawancara tersebut, diketahui bahwa buku paket yang mereka jadikan sumber rujukan dalam proses perkuliahan menggunakan bahasa yang sulit dipahami oleh mahasiswa dan kurang interaktif. Selain memperoleh informasi dari wawancara yang dilakukan kepada dosen pengampu geometri analitik bidang dan ruang dan mahasiswa, juga diperoleh data dari tes awal yang dilakukan. Pada tes awal ini, hanya 3 dari 20 mahasiswa yang mendapat nilai lebih dari 75 . Dan rerata nilai yang diperoleh mahasiswa adalah
50.05 yang bila dikonversikan ke nilai interval $1-4$ adalah 2.50. Nilai ini sangat jauh dari kategori cukup. Nilai ini menunjukkan bahwa kemampuan kemampuan pemahaman konsep mahasiswa masih kurang.

Untuk menanggulangi permasalahan yang dialami oleh mahasiswa ini, maka dikembangkan modul yang diharapkan bisa membantu mahasiswa untuk menguasai materi yang selama ini dianggap susah. Penelitian ini akan mengembangkan modul berdasarkan teori Van Hiele. Pengaplikasian teori ini dipercaya mampu menanggulangi kesulitan para mahasiswa menguasai konsep geometri. Teori ini menerangkan perkembangan cara berpikir dari seseorang saat belajar tentang geometri (Muhassanah, 2014). Tidak hanya itu, teori Van Hiele juga menjadi teori belajar tunggal yang mengkhusus kepada geometri (Halim, 2017). Teori inipun merupakan teori paling lengkap yang menjelaskan keterampilan dalam belajar geometri (Argaswari, 2018)

Teori Van Hiele ini ada 5 tahapannya, yaitu tahap identifikasi. Pada tahap ini seseorang mengenal bentuk-bentuk geometri hanya sekedar visual dari suatu objek (Anisya, 2016). Ciri peserta didik di tahapan ini adalah mereka mulai terbiasa untuk memahami gambaran objek secara umum, tapi belum tahu sifat dari gambaran objek tersebut (Fitriyani et al., 2018). Tahap analisa adalah tahap seseorang memhami rancangan serta karateristik dari bentuk geometri (Sudihartinih \& Mulyana, 2014). Hal ini berarti peserta didik sudah belajar sifat dari bentuk objek dan sudah mampu menuturkan keteraturan yang ada dalam bentuk objek itu (Fitriyani et al., 2018). Tahap pengurutan merupakan tahap dimana seseorang mulai mampu mengaitkan 
karakteristik dari beberapa bangun ruang, membuat arti yang masih abstrak, menciptakan karakteristik dari macam-macam bangun memakai deduksi informal serta mampu mengelompokkannya dengan berurut. Karena geometri merupakan ilmu deduktif, maka pengambilan kesimpulam, pembuktian teorema dan lain-lain harus dilakukan secara deduktif (Anisya, 2016). Tahap keakuratan, peserta didik dapat memahami sistem non eucliden dalam hal struktur aksioma murni (Musdi \& Gusnita, 2018).

Selain membahas tahap berpikir, teori Van Hiele juga membahas mengenai fase-fase pembelajaran geometri yakni fase informasi, lalu fase orientasi secara langsung, fase deskripsi, dan keempat fase orientasi lagi, kemudian kelima kombinasi (Halim, 2017). Fase-fase tersebut bertujuan guna menumbuhkan kepiawaian berpikir dari suatu tahapan berpikir geometri peserta didik ke tingkatan berpikir yang lebih (Ramlan, 2016)

Sudah ada beberapa hasil penelitian lain yang serupa, diantaranya yang diadakan oleh Maula (2018) menunjukkan bahwa analisis hasil belajar peserta didik setelah memakai materi ajar geometri Van Hiele dalam proses pembelajaran membuktikan bahwa beberapa dari peserta didik mendapatkan nilai di atas KKM, yaitu 60. Tidak hanya itu penelitian yang lain dilaksanakan oleh Argaswari (2018), menunjukkan modul efektif meningkatkan level berpikir geometri sebanyak $48 \%$ peserta didik.

Pengembangan modul berdasarkan teori Van Hiele ini bertujuan menghasilkan modul yang valid, praktis dan efektif. Modul ini didesain untuk meningkatkan kemampuan berfikir geometri mahasiswa sehingga mahasiswa lebih mudah memahami materi konikoida.

\section{METODE PENELITIAN}

Tipe penelitian yang dipakai ialah Research \& Development model Plomp. Penggunaan model pengembangan Plomp sebab model ini sangat sesuai dengan penelitian pengembangan yang berhubungan dengan pembelajaran serta memiliki kelebihan yaitu uraiannya tampak lebih lengkap dan sistematis (Rochmad, 2012). Model ini terdiri atas beberapa langkah, mulai penyelidikan awal, rancangan, realisasi, serta tes evaluasi (Plomp, 1997). Produk dalam pengembangan ini ialah modul geometri analitik bidang dan ruang materi konikoida berdasarkan toeri Van Hiele. Dengan subjek uji coba yaitu mahasiswa semester III jurusan Pendidikan Matematika UIN Alauddin Makassar Tahun Ajaran 2019/2020 dengan jumlah 77 orang terdiri dari kelas Matematika 1.2 berjumlah 41 orang. Kelas Matematika 3.4 berjumlah 36 orang.

Instrumen yang digunakan untuk penelitian ini ialah: 1) lembar validasi untuk mengukur kevalidan modul dan instrumen lainnya, 2) lembar observasi keterlaksanaannya pembelajaran, angket untuk respon mahasiswa juga dosen guna mengukur kemudahan pemakaian modul, 3) lembar observasi aktivitas mahasiswa juga dosen, serta tes pemahaman konsep guna mengukur tingkat keefektifan modul.

Teknik pengumpulan data yang digunakan pada penelitian ini ialah angket, observasi, dan tes hasil belajar. Angket yang digunakan dalam penelitian ini berupa angket respon mahasiswa dan angket respon dosen. Observasi dilakukan secara terstruktur, yaitu observasi yang telah dirancang 
secara sistematis, tentang apa yang akan diamati, kapan dan dimana tempatnya yaitu, berupa lembar observasi aktivitas mahasiswa, lembar observasi keterlaksanaan bahan ajar dan lembar observasi kemampuan dosen mengelola pembelajaran. Tes hasil belajar digunakan untuk mengukur hasil belajar mahasiswa dengan menggunakan modul geometri analitik bidang dan ruang pokok bahasan konikoida berdasarkan teori Van Hiele.

Analisi data yang digunakan pada penenelitaian ini adalah analisis deskriptif kualitatif dan kuantitatif. Analisis secara deskriptif kualitatif dipakai guna menguraikan data mulai dari catatan, saran perbaikan, ataupun komentar hasil penelitian yang ada di lembar instrumen. Sebaliknya, analisis secara kuantitatif dipakai untuk menganalisis data hasil validasi dengan syarat minimal berada pada kategori valid, hasil observasi minimal berada pada kategori terlaksana sebagian, angket respon mahasiswa dan dosen yang memiliki respon positif, dan hasil pengolahan tes pemahaman konikoida dengan syarat, $70 \%$ mahasiswa memperoleh nilai minimal 75 .

Awal proses pembelajaran, mahasiswa diperihatkan gambar-gambar konikoida dan diminta kepada mahasiswa untuk menyebutkan nama dari bangun yang diperlihatkan, kegiatan ini disebut tahap pengenalan. Fase ini semua mahasiswa bisa melafalkan nama-nama bangun yang diperlihatkan. Artinya semua mahasiswa telah melewati tahap pengenalan yang ditandai dengan mampunya para mahasiswa mengenal bentuk-bentuk bangun yang diperlihatkan. Sesaui dengan penelitian yang dilakukan oleh Khaerani (2010), dimana fase ini seseorang mampu memahami bentuk geometri sesuai dengan ciri-ciri penampakan dan visualnya (tidak berpusat pada sifat objek pengamatan, melainkan memandang objek secara utuh. Setelah melalui tahap pengenalan, mahasiswa diminta untuk melafalkan sifat bangun yang diperlihatkan sebelumnya. Kegiatan ini, disebut tahap analisis. Tahap ini, ditandai dengan adanya kemampuan menganalisis mahasiswa terhadap konsep dan karakteristiknya. Hal ini sesuai dengan hasil penelitian dari Kho (2020), yaitu pada fase ini berangsur-angsur mengenalkan struktur yang memberi ciri-ciri suatu bangun geometri kepada peserta didik. Untuk memberi pemahaman lebih ke mahasiswa, dosen menjelaskan definisi bangun yang ada pada modul.

Setelah memahami definisi tersebut selanjutnya dosen menjelaskan tentang contoh soal, dan kegiatan ini disebut tahap pengurutan. Mahasiswa yang memasuki tahap pengurutan, belum mampu menyelesaikan contoh soal berdasarkan teorema yang ada. Agar mampu menyelesaikan soal-soal sesuai teorema, mahasiswa harus memahami teorema-teorema yang ada. Tahapan ini disebut tahap deduksi, dimana mahasiswa mampu menyusun penyelesaian soal berdasarkan teorema. Mahasiswa yang telah memasuki tahap deduksi telah mampu mengurutkan bukti, bukan sekedar menerima bukti. Sesuai dengan penelitian yang dilakukan oleh Kho (2020), pada fase ini telah mampu menggunakan bahasa yang tepat dan akurat. Setelah melalui empat tahap sebelumnya, mahasiswa mencapai tahap yang tertinggi yaitu tahap keakuratan. Dimana fase ini mahasiswa sudah berpikir logis dengan benar dalam sistem matematika serta bisa menguraikan konsekuensi dari definisi dan manipulasi aksioma (Watan \& Sugiman, 2018) . 
DOI: https://doi.org/10.24127/ajpm.v10i2.3438

\section{HASIL DAN PEMBAHASAN}

Pengembangan modul geometri analitik bidang dan ruang berdasarkan teori Van Hiele mengadaptasi model Plomp. Proses pengembangan dilakukan mulai dari:

\section{A. Penyelidikan Awal}

Tujuannya untuk menganalisa masalah-masalah yang dialami dan halhal yang menjadi kebutuhan subjek yang diteliti (mahasiswa pendidikan matematika) khususnya dalam mata kuliah geometri analitik bidang dan ruang bahasan Konikoida. Berdasarkan hasil wawancara dosen, mahasiswa mengalami kesulitan dalam memahami konsep-konsep dalam materi geometri analitik ruang. Dan mahasiswa belum mampu mengidentifikasi bentuk-bentuk permukaan dari jenis-jenis konikoida. Selain itu, menurut mahasiswa Pendidikan Matematika buku paket yang digunakan dalam proses perkuliahan menggunakan bahasa yang sulit dipahami sehingga mahasiswa kesulitan dalam memahami materi geometri analitik bidang dan ruang.

\section{B. Desain}

Pada fase ini dilakukan perancangan modul geometri analitik bidang dan ruang berdasarkan teori Van Hiele dan perangkat yang digunakan pada kegiatan pembelajaran serta penyusunan instrumen penelitian. Format RPP yang dipakai adalah pembelajaran kooperatif (Cooperative Learning) yang didalamnya memuat kemampuan akhir yang diinginkan, indikator, materi ajar, model pembelajaran, sumber belajar serta langkah-langkah pembelajaran. Untuk sampul modul, disusun sesuai dengan unsur-unsur yang wajib ada pada sampul yaitu judul buku, nama penulis, penerbit, penjelasan singkat, dan desain atau ilustrasi. Sedangkan untuk isi modul disesuaikan dengan kebutuhan serta kompetensi yang hendak dicapai. Modul yang dihasilkan harus bisa membantu mahasiswa untuk mencapai kompetensi dan bisa membantu mahasiswa belajar meskipun tanpa bimbingan dari dosen. Setelah menyusun isi modul, langkah selanjutnya adalah penyusunan instrumen penelitian.

\section{Realisasi}

Dalam fase ini, modul beserta instrumen penelitian yang sudah dibuat dalam fase rancangan dinamakan prototipe 1 kemudian divalidasi oleh validator sebelum benar-benar digunakan. Hasil penilaian validator terhadap instrumen yang digunakan dalam penelitian ini dapat dilihat pada Tabel1.

Tabel 1. Hasil penliaian validator

\begin{tabular}{|c|c|}
\hline $\begin{array}{l}\text { Instrumen yang di } \\
\text { validasi }\end{array}$ & Hasil Validasi \\
\hline Bahan Ajar & $\begin{array}{l}\text { - } \text { Menambahkan } \\
\text { penjelasan mengenai } \\
\text { teori Van Hiele pada } \\
\text { bagian pendahuluan } \\
\text { - Lebih memperbanyak } \\
\text { contoh soal }\end{array}$ \\
\hline RPP & $\begin{array}{l}\text { - Menambahkan } \\
\text { indikator dan } \\
\text { kemampuan akhir } \\
\text { - Indikator disesuaikan } \\
\text { dengan KKO }\end{array}$ \\
\hline
\end{tabular}

Berikut adalah isi dari modul berdasarkan teori van hiele:

1. TahapVisualisasi (Pengenalan)

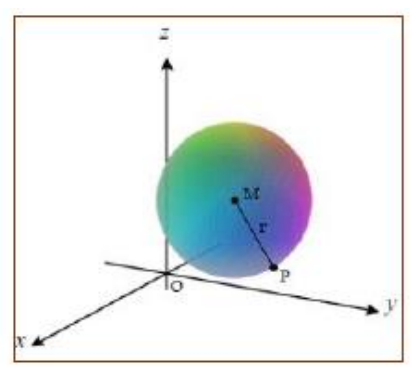

Gambar 1. Bangun bola 
DOI: https://doi.org/10.24127/ajpm.v10i2.3438

Ilustrasi yang disediakan dalam modul dapat membantu mahasiswa untuk lebih mengenal nama bangun geometri seperti pada Gambar 1.

2. Tahap Analisis

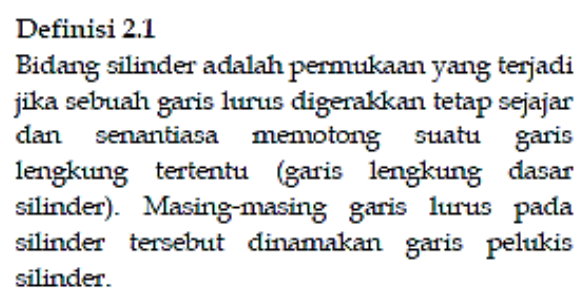

Gambar 2. Definisi bangun silinder

Pada modul juga terdapat definisi masing-masing bangun, agar mahasiswa dapat mengetahui definisi dari bangun tersebut tidak hanya mengenal bentuknya seperti pada Gambar 2 .

\section{Tahap Pengurutan}

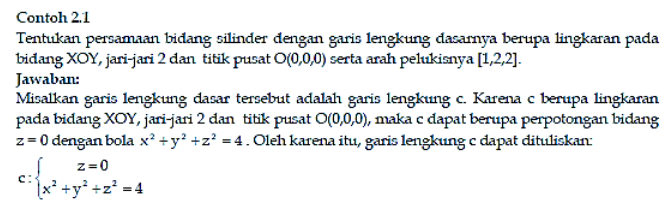

Gambar 3. Contoh soal dan jawaban

Terdapat beberapa contoh soal beserta dengan jawabannya agar mahasiswa lebih mudah memahami materi yang disampaikan pada modul seperti pada Gambar 3.

\section{Tahap Deduksi}

Tersedia pula teorema-teorema agar mahasiswa dapat menyelesaikan permasalahan sesuai dengan urutan (teorema) seperti pada Gambar 4.

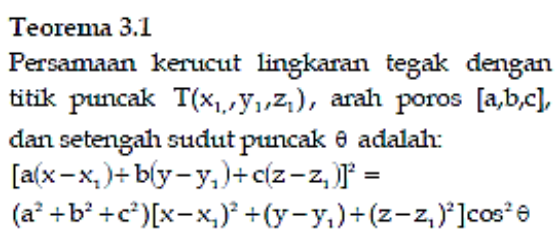

Gambar 4. Teorema

\section{Uji Coba, Evaluasi, serta Peninjauan Kembali}

Prototipe 1 yang telah didapatkan pada tahap sebelumnya selanjutnya divalidasi untuk memenuhi syarat pertama yaitu kevalidan. Hasil penilaian dari validator terhadap modul geometri analitik bidang dan ruang materi konikoida berdasarkan teori Van Hiele memperoleh rata-rata penilaian 4,50 dengan kategori sangat valid. Hal ini berarti instrumen yang dikembangkan baik dan layak digunakan pada tahap selanjutnya.

Setelah dinyatakan valid, selanjutnya modul yang telah dikembangkan beserta instrumennya kemudian diujicobakan kepada mahasiswa Jurusan Pendidikan Matematika kelas Matematika 1 dan Matematika 2 yang dilaksanakan selama 3 hari. Hasil analisis untuk tingkat kepraktisan dan keefektifan modul bisa dilihat pada Tabel 2 dan Tabel 3.

Tabel 2. Hasil analisis tingkat kepraktisan

\begin{tabular}{clcc}
\hline No & \multicolumn{1}{c}{$\begin{array}{c}\text { Lembar } \\
\text { Penilaian }\end{array}$} & $\begin{array}{c}\text { Rata- } \\
\text { rata }\end{array}$ & Kategori \\
\hline 1 & $\begin{array}{l}\text { Observasi } \\
\text { Keterlaksanaan }\end{array}$ & 1,56 & $\begin{array}{c}\text { Terlaksana } \\
\text { Seluruhnya }\end{array}$ \\
& $\begin{array}{l}\text { Pembelajaran } \\
\text { Angket Respon }\end{array}$ & 82,68 & Positif \\
& $\begin{array}{l}\text { Mahasiswa } \\
\text { Angket Respon }\end{array}$ & 86,94 & $\begin{array}{l}\text { Sangat } \\
\text { Positif }\end{array}$ \\
\hline & Dosen & & \\
\hline
\end{tabular}

Tabel 3. Hasil analisis tingkat keefektifan

\begin{tabular}{clcc}
\hline No & Lembar Penilaian & $\begin{array}{c}\text { Rata- } \\
\text { rata }\end{array}$ & Kategori \\
\hline \multirow{2}{*}{1} & $\begin{array}{l}\text { Lembar Observasi } \\
\text { Aktivitas }\end{array}$ & 80,125 & $\begin{array}{c}\text { Sangat } \\
\text { Baik }\end{array}$ \\
& $\begin{array}{l}\text { Mahasiswa } \\
\text { Kemampuan }\end{array}$ & 4,00 & Positif \\
2 & $\begin{array}{l}\text { Dosen Mengelola } \\
\text { Pembelajaran }\end{array}$ & & \\
& Ketuntasan & $75 \%$ & Sangat \\
3 & $\begin{array}{l}\text { Klasikal Tes } \\
\text { Pemahaman }\end{array}$ & & Tinggi \\
& Konsep & & \\
\hline
\end{tabular}


Dari Tabel 2 dan Tabel 3 dapat dilihat bahwa instrumen yang dikembangkan telah memenuhi syarat untuk dapat dikatakan praktis dan efektif. Berdasarkan hasil analisis tingkat kepraktisan dan keefektifan, maka modul yang telah dikembangkan sudah memenuhi syarat dan kelayakan untuk digunakan dalam proses pembelajaran. Berdasarkan data pada Tabel 2 dapat dilihat bahwa instrumen yang dikembangkan telah memenuhi syarat untuk dikatakan praktis. Untuk hasil analisis dari ketiga tolak ukur keefektifan. maka bahan ajar yang telah dikembangkan sudah memenuhi kriteria.

Penelitian ini menghasilkan modul geometri analitik bidang dan ruang pada materi konikoida yang dirancang berdasarkan teori Van Hiele dan telah memenuhi kriteria valid, praktis dan efektif. Hal ini disebabkan karena dalam setiap tahapan Plomp peneliti telah memperhatikan dengan baik setiap detailnya dengan menggunakan instrumen yang sesuai. Kekurangan dalam penelitian ini karena fokus materi terbatas hanya pada bahasan konikoida, serta tidak menyandingkan dengan model pembelajaran yang sesuai dengan tingkatan mahasiswa. Penelitian Saltifa (2020) sejalan dengan hasil penelitian peneliti yang menyimpulkan modul geometri analitik yang digunakan berdasarkan model pengembangan Plomp telah valid, praktis dan efektif, dan yang membedakan dengan hasil penelitian ini yaitu peneliti fokus pada peningkatan hasil belajar pada materi konikoida. Selanjutnya Argaswari (2018) menyimpulkan modul pembelajaran geometri berdasarkan teori Van Hiele telah memenuhi kriteria valid dan efektif dengan mengikuti model pengembangan Bold\&Gall, yang membedakan dengan hasil penelitian ini yaitu peneliti menggunakan model Plomp. Adapun implikasi dari hasil penelitian ini yaitu tersedianya modul yang telah teruji kriteria valid, praktis dan efektif sehingga dapat digunakan dalam pembelajaran geometri analitik ruang dan bidang agar hasil belajar dapat meningkat karena detail materi telah di paparkan dengan baik berdasarkan teori Van Hiele.

\section{KESIMPULAN DAN SARAN}

Adapun kesimpulan dari penelitian ini diperoleh sebuah modul yang memenuhi kategori valid, praktis dan efektif yang dapat digunakan dalam pembelajaran matematika pada materi Konikoida.

Disarankan untuk penelitian selanjutnya agar produk ini bisa dikembangkan pada pokok bahasan lain yang masih berada dalam ruang lingkup geometri. Dan peneliti selanjutnya dapat melanjutkan dengan menvariasikan dengan model pembelajaran yang sesuai dengan karakter mahasiswa.

\section{DAFTAR PUSTAKA}

Anisya, R. K. (2016). Pengembangan Bahan Ajar Berbasis Masalah pada Materi Geometri Berdasarkan Lever Berpikir Geometri Van Hiele. UIN Raden In tan Lampung.

Argaswari, D. P. A. . (2018). Development of module of learning Geometry Based On Van Hiele Theory. Daya Matematis, 2, 276-285.

Fitriyani, H., Widodo, S. A., \& Aan Hendranto. (2018). Students' Geometric Thinking Based On Van Hiele's Theory. Infinity: Journal of Mathematic Education, 7(1), 55-60. 
Halim, F. A. (2017). Efektivitas Pembelajaran yang menggunakan teori van hiele ditinjau dari minat dan hasil belajar siswa pada materi segitiga di kelas VII $B$ SMP BOPKRI 1 Yogyakarta Tahun Ajaran 2016/2017. Universitas Sanata Dharma.

Khaerani. (2010). Efektifitas Penerapan Teori Van Hiele pada Peningkatan Hasil Belajar Matematika Pokok Bahasan Geometri Siswa Kelas VII SMP Negeri 13 Makassar. UIN Alauddin Makassae.

Kho, R. (2020). Pengembangan Bahan Ajar Geometri Tiga Dimensi berdasarkan Lima Fase Model van Hiele untuk Menumbuhkembangkan

Penalaran Visuospasial. JISIP (Jurnal Ilmu Sosial Dan Pendidikan), 4(2), 101-105. https://doi.org/10.36312/jisip.v4i2 .1073

Machromah, I. U. (2018). Implementing Van Hiele Theory on Circle Module. ICRIEMS Proceedings.

Maula, I. (2018). Pengembangan Bahan Ajar Geometri Van Hiele. Inspiramatika, 4(1), 39-46.

Muhassanah, N. (2014). Analisis Keterampilan Geometri Siswa dalam Memecahkan Masalah Geometri berdasarkan Tingkat Berpikir Van Hiele. Jurnal Elektronik Pembelajaran Matematika, 2(1), 54-57.

Musdi, E., \& Gusnita, N. (2018). Development of Mathematical Learning Devices Using Van Hiele Theory in Geometry of The Students In Grade VIII Secondary High School. Advances in Social Science, Education and Humanities Research (ASSEHR), 285(2), 54-57.
Plomp, T. (1997). Educational Design: Introduction. From Tjeerd Plomp (eds). Educational \& Training System Design: Introduction. Lemma.

Ramlan, A. M. (2016). The Effect Of Van Hiele Learning Model Toward Geometric Reasoning Ability Based On Self-Efficacy Of Senior High School Students. Journal Of Mathematics Education, 1(2), 63-72.

Rochmad. (2012). Desain Model Pengembangan Perangkat Pembelajaran Matematika. Jurnal Kreano, 3(1), 59-72.

Saltifa, P. (2020). Pengembangan Modul Geometri Analitik Bidang Berorientasi Pada Kemampuan Pemahaman Matematis Mahasiswa Development of Analytic Geometry Module Oriented In Students , mathematics Understanding. Jurnal Equation: Teori dan Penelitian Pendidikan Matematika, 3(1), 34-45.

Sudihartinih, E., \& Mulyana, E. (2014). Perkuliahan Geometri Transformasi Dengan Pendekatan Kontruktivisme Untuk Meningkatkan Level Berpikir Geometri Van Hiele. Jurnal Pendidikan Matematika Sigma Didaktika, 3(1), 12-16.

Watan, S., \& Sugiman. (2018). The Van Hiele Theory and Realistic Mathematics Education: As Teachers' Instruction for Teaching Geometry. AIP Conference Proceedings.

Yudianto, E. (2017). The Identification of Van Hiele Level Students On the Topic ofSpace Analytic Geometry. International Conference on Mathematics. 